\title{
The Ear
}

and tongue and right vocal cord. Difficulty in swallowing solids, but not in swallowing liquids.

Mr Somerville Hastings (President) said that the paralysis might be due to an ingrowth of the malignant disease through the walls of the skull into the cranial cavity. He suggested that a small part of the granulation tissue should be removed for microscopical examination; he had never seen a similar case.

$\mathrm{Mr} \mathrm{H}$. V. FORSTER said that one could see the choana and the Eustachian orifice on the left, but not on the right side, for there alteration had occurred owing to some smooth swelling, or because some swelling was pushing the Eustachian cushion inwards. He thought the trouble was affecting the base of the skull. A patient who had been treated for some time for lymphadenoma had been sent to him. She had right-sided deafness and right trifacial neuralgia, and in her case he found that the Eustachian cushion was being pushed. The patient had died shortly afterwards.

\section{ABSTR ACTS}

\section{THE EAR.}

The action of Hartmann's Curved Tympanic Cannula in Purulent Cholesteatoma of the Ear, checked by means of Röntgenography. Dr Birkholz, Aschersleben. (Zeitschrift für Hals-, Nasen-, und Ohrenheilkunde, Band xxii., Heft 3, p. 326.)

Although fluids may be injected into glass tubes open at both ends by means of Hartmann's tympanic tubes, this can only be effected by a very slight degree if the further end of the glass tube is sealed. In living subjects affected with suppurating cholesteatoma only a very superficial cleansing can be carried out, as the Röntgen pictures of injected lipiodol or even the much thinner Umbrenal (Iodinelithium) do not penetrate to any useful distance into the cholesteatoma cavity. Birkholz would, therefore, throw aside the tympanic cannula as a rational method of treatment, while admitting its value for cleansing purposes.

James Dundas-Grant.

\section{Dott. Francesco D'Onofrio. (Archivio Italiano di Otologia, October 1928.)}

A series of observations on the hearing powers of normal subjects and of persons suffering from catarrhal middle-ear disease at sea-level and at about three thousand feet has shown that the normal subjects had a greater acuity of hearing at the higher level, and that this was even more marked in the catarrhal cases. The author considers that this is due to Eustachian congestion at the lower levels, and that this 


\section{Abstracts}

itself is due to greater humidity and to the presence in the air of iodine and sodium chloride.

In the normal subject the hearing distance was increased by from Io per cent. to 30 per cent. at the higher altitudes, and in the catarrhal cases the improvement was from 50 to 100 per cent.

In these catarrhal cases there was a definite and lasting improvement after a sojourn for some months in the higher regions.

F. C. ORMEROD.

The beginning of Otosclerotic Bone-disease, histologically investigated.

Dr Döderlein, Frankfort. (Zeitschrift für Hals-, Nasen-, und Ohrenheilkunde, Band xxii., Heft 3, p. 293.)

The characteristic otosclerotic changes are found in their earliest stage round the blood vessels. This is well shown if a thionin stain is employed. There appears to be no sign of neoplastic bone formation, but rather a regressive process. Out of a very large number of examinations of children's temporal bones not one under the age of four years showed otosclerotic changes. The condition, therefore, does not consist in a transmitted error in construction and develops first in the course of post-embryonic life. Examination with thionin staining shows osseous changes which coincide to a striking extent with those of rickets and osteomalacia. Such differences as there are, are those depending on the peculiarities of the bone of the labyrinthcapsule as compared with the bone of the skeleton in general. Two coloured microscopical sections are appended in illustration.

James Dundas-Grant.

On "Compensation" Nystagmus occurring in the Rotation Tests after Complete Loss of Labyrinth Function, and its Inference. $\mathrm{N}$. Rosenblatt, Odessa. (Mschr. Ohrenheilk., November 1928.)

The puzzling problem which surrounds the occurrence of partial or complete compensation to the effects of Rotation, after total loss of the labyrinth on one side, has prompted the author to analyse six cases, illustrating this condition.

The article is prefaced with a brief historical survey dating back to r 907, which thus covers the period during which these investigations have formed a part of our clinical examination. Although unfortunately he has been unable to decide definitely for himself the precise point on which such compensation depends (that is as to whether it is situated peripherally or centrally, and the rationale or inference of the same) the article provides an excellent short summary of the difficulties surrounding these phenomena; and the account of the cases forms a good basis for comparison with our own clinical work, with a view to attempting to solve this most difficult proposition. A short criticism

$$
278
$$




\section{The Ear}

accompanies each case and the article terminates with the following conclusions :--

I. As already recognised, compensation to the Rotation Tests does not necessarily indicate complete healing of an affected labyrinth. Even with compensation, a latent labyrinthitis may give rise to intracranial complications.

2. With the removal of a complete sequestrum of the labyrinth (as determined both by clinical and anatomical examination) compensation may not always be established.

3. The presence of compensation does not always mean loss of function of all the terminations of the vestibular nerve.

4. Compensation is not established in respect of all the canals simultaneously. The horizontal canals are the first to be compensated.

5. The co-existence of a chronic Otorrhœa (not giving rise to urgent symptoms) with a loss of function of the corresponding labyrinth, indicates that surgical interference should be avoided if possible.

6. If, however, a middle-ear operation has to be performedunder the conditions described in the preceding paragraph - this should be followed by a preliminary opening and examination of the inner ear and further procedure should be guided by the result of such inspection.

Alex. R. Tweedie.

Disturbances of the Vestibular Apparatus and recent work. M. LANos.

(Annales des maladies de l'oreille, du larynx, du nez et du pharynx. July, I928.)

Recent researches have been directed to the co-ordination of results in the systematic examination of the vestibular reactions to the experimental tests with one another, and with the spontaneous reactions presented by the patient, and to the study of these reflexes not only from the point of view of nystagmus, but of the other reactionary movements, spontaneous or provoked. Only by so doing can one hope to arrive, though still too rarely, at a relatively precise diagnosis of the site and nature of a lesion.

The author reminds us that, although every vestibular lesion (with a few exceptions) is accompanied at some given moment by disturbances of equilibrium, it does not follow that every loss of equilibrium is of vestibular origin, since equilibrium depends on many other sensations -visual, tactile, auditory, and, chiefly, deep muscular and articular sensibility. In studying the vestibular function by means of experimental tests, it is better to employ a minimal stimulus (caloric, rotatory, or galvanic) to provoke the threshold of reaction of each vestibule; 


\section{Abstracts}

moreover, the close study of spontaneous disturbances of equilibrium is indispensable since this often reveals lesions at their onset.

The double nature of the vestibular apparatus with its harmony of function between the two organs allows the phenomenon of compensation; this must be taken into account in all tests. Again, he points out that the vestibular reflexes depend on two different groups : reflexes of movement on the semicircular canals (ampullæ), reflexes of posture on the otoliths (sagittæ and lapilli).

Next, the author analyses the different elements of the vestibular syndrome, viz.: nystagmus, reactionary movements of deviation and falling, and the associated subjective disturbances, vertigo, nausea, pallor, sweating, etc. When this syndrome exists spontaneously it reveals the certain existence of a disturbance of vestibular function and therefore of a pathological lesion which may be either peripheral or central. When not spontaneous the experimental tests in producing it allow us to study its different characters, for it is then a reflex which is abnormal if, in certain of its elements, it differs from the reflex vestibular phenomena usually observed. Hence, in the clinical examination of persons suffering from vertigo, after the study of the spontaneous disturbances it is necessary to proceed to the study of the provoked disturbances in order to obtain equally important results.

The author describes the latest work on the experimental tests, caloric, rotatory, galvanic, and reactionary movements of the limbs, and compares them with one another. He then groups the principal elements of the vestibular reflex by which one recognises hyper- or hypo- excitability of the organ in relation to various lesions, e.g., labyrinthine fistula, auricular syphilis, cerebro-spinal meningitis, mumps, angiospasm, and certain endocraniai or central affections, tumours of the cerebello-pontine angle, disseminate sclerosis, encephalitis lethargica, syringo-bulbia, and finally the neuroses.

A complete bibliography of the recent works on the subject consulted is given.

L. Graham Brown.

Motor Trigeminal Nerve Lesions of Otitic Origin. Lannors and Jouve. (Ann. des maladies de 'oreille, etc., July 1928.)

The writers remark that, while sensory disturbances, such as Gradenigo's syndrome, are well known, the rarer motor lesions are not always recognised. Such lesions may be either spasmodic or paralytic. The first, spasms and trismus, may be due to temporomandibular arthritis, to the spread of mastoiditis into the digastric groove, or to infiltration from the region of the posterior lacerate foramen, with or without jugular bulb thrombosis. Also, there may be an irritation of the motor root at the apex of the petrous.

The paralyses are more important, and are due to lesions of the 280 


\section{The Nose and Accessory Sinuses}

motor root at the apex of the petrous. The symptoms are facial asymmetry, with flatness in the temporal fossa and postero-lateral part of the cheek, due to atrophy of masseter and temporal; the paralysis is revealed by absence of contraction of the muscles during opening and closing the mouth, and by the subluxation of the corresponding joint.

The authors describe fully three cases due to middle-ear suppuration, and show how the spread of inflammation to the apex of the petrous can affect the motor root in its suprapetrosal course, where it is in direct contact with the bone for 7 to $8 \mathrm{~mm}$. L. Graham Brown.

Immediate Closure of the Wound in Operation for Acute Mastoiditis. C. Borri. (Archivio Italiano di Otologia, December 1928, Vol. xxxix., fasc. I2.)

The author describes ten cases of acute mastoiditis in which he performed the Schwartze type of operation, and sutured the postauricular wound, leaving a thin rubber tube with lateral holes and a wick of gauze at the lower end of the wound. The upper end of the tube was placed in the cavity of the mastoid antrum, the other projected from the wound. There was always discharge from the tube, but it usually ceased about the tenth or twelfth day and the drain was left out.

Of the ten cases, all except one did well, and complete healing was observed in from twelve to nineteen days, with good hearing and an intact drumhead. The tenth case showed signs of inflammation on the twelfth day; the cavity was found to be full of pus-which was evacuated and the cavity again closed---it healed without further trouble.

The author displays only moderate enthusiasm for the procedure, but thinks it useful in chosen cases of acute infection with short history of middle-ear trouble. He considers that much care must be given at the same time to disinfection of the nose and nasopharynx.

F. C. Ormerod.

\section{THE NOSE AND ACCESSORY SINUSES.}

Chronic Ethmoiditis. Ross Hall Skillern, M.D. (Brit. Med. Journ., 29th September 1928.) (Discussion at B.M.A. Meeting, Cardiff.)

Chronic infections of the ethmoid can be broadly divided into the suppurative and non-suppurative types. The former, associated with the presence of leucocytic pus, has been long recognised, but the latter has been identified only in more recent times, characterised as it is by polypoid hypertrophy and even true polypi, but without pus. At the same time it must be remembered that the two forms may merge, the hypertrophic form giving rise to conditions which favour the growth 


\section{Abstracts}

of saprophytic organisms. The writer further subdivides the suppurative type into three classes according to the involvement of the anterior or posterior group of ethmoid cells or the involvement of both, while the non-suppurative type he divides not only anatomically, but according to whether the infection is intracellular or extracellular or combined, and again as to whether suppuration has supervened. Suppuration confined to one or more of the anterior cells is practically never found except in the case of the bulla ethmoidalis. The posterior cells are much more frequently infected than the anterior, probably because they are larger and more numerous, and also because they are so situated as to be less amenable to aeration. Being but slightly disturbed by the inspiratory air currents, they offer a fine site for the growth of organisms once infection has taken place. The successful treatment of all sinus infection has for its basic principles aeration and drainage, with emphasis on the former. The attempt to remove all infected tissue, irrespective of the kind and extent of the inflammatory process, is to be deprecated. More recent experience has shown that with proper assistance nature will do much to bring about a resolution of the mucosa in diseased cells when proper aeration has been established. This has been abundantly proved in work on the sphenoidal sinus where a simple opening of the anterior wall leads in a few days to disappearance of the polypoid hypertrophy of the lining mucosa. The writer depends largely in early cases on removal of the middle turbinate, followed in a few days by tamponage with cotton mops soaked in a solution of a non-irritating silver salt with glycerine. After healing has taken place, if suppuration is found to be present in the posterior ethmoid cells, these are opened by means of a hook, and only the diseased tissue removed by forceps. In old cases, with infection of the whole labyrinth, nothing less than a complete exenteration will suffice. In these cases the preliminary removal of the uncinate process is of great help by giving additional exposure. The particular method of exenteration is left to the choice of the operator. The writer is not impressed by the fear of meningitis arising from infection along the sheath of the olfactory nerve. While admitting the possibility, he has not met with the occurrence. He prefers in all cases the intranasal operation.

T. Ritchie Rodger.

The Influence of the Structure of the Soft Palate on Nasal Respiration and its Significance in Nasal Disease. (Hypertrophy of the Soft Palate.) Maljutin, Moscow. (Otolaryngologia Slavica, Vol. i., fasc. I, p. 50.)

In many cases of nasal obstruction and catarrhal conditions not otherwise relieved, the writer considers that hypertrophy of the palate is to blame. He examined 103 healthy young soldiers in regard to 


\section{The Nose and Accessory Sinuses}

this; in 35 there was excessive strength of the palate, which made digital investigation of the nasopharynx almost impossible. These subjects complained of difficulty in nasal respiration with frequent attacks of coryza without apparent cause. In other 36 , there was a thin delicate soft palate, and of them 28 had healthy noses. In the other 8, adenoid vegetations were found which gave rise to no symptoms. In 32 with moderate development of the palate the finger could be introduced into the nasopharynx with comparative ease. In 8 of them there were adenoid vegetations; 5 had occasional attacks of coryza and in 7 there was ethmoiditis. The other 12 were healthy. This excessive development of the soft palate seems to be congenital and hereditary. Some of the patients were remarkable for the shortness of their necks; others were gouty.

In searching for treatment for the condition the writer happened to remove adenoids in one of these cases, tearing away at the same time the posterior layer of the thickened soft palate, after which the patient experienced complete relief. The portion removed contained the middle part of the azygos and part of the other underlying muscles. $\mathrm{He}$ accordingly devised an operation to produce the same effect, making an incision parallel to the margin of the palate and a vertical one at right angles to this. The mucous membrane was detached towards both sides and a portion of the exposed mass of muscle cut away with a scalpel and sometimes by means of Browne's lingual tonsil guillotine. The results seem often to be extremely good, but in patients who refuse this operation, he adopted, as a substitute for it, systematic stretching and compression of the soft palate by means of the middle and index finger.

He suggests for the condition the name "Hypertrophia Palati Mollis" (soft palate hypertrophy) or, shorter, "Velitis." (! sit venia, J. D. G.)

James Dundas-Grant.

\section{The Effect on the Olfactory Centre and Bulb of an Experimental Frontal Sinusitis. Dott. Tonio MagnotT. (Archivio Italiano di Otologio, November 1928 .)}

Experiments on various animals consisted in producing an acute frontal sinusitis by introducing a virulent culture of staphylococcus. The animals were killed after periods of from one to two months. Marked changes were found in the olfactory bulb on the same side, the fibrillary and glomerular layers had been replaced by fibrous tissue, and the whole bulb showed signs of degeneration. The bulb of the opposite side showed areas of degeneration in the fibrillary and glomerular areas, but the rest of the bulb appeared normal. There were also degenerative changes in the macula lutea on the same side. Careful examination of the cortical centre of smell failed to show any changes.

F. C. Ormerod. 


\section{Abstracts}

Pseudo-membranous Non-diphtheritic Rhinitis. R. Bertoln. (Annales des maladies de loreille, du larynx, du nez et du pharynx, July I 928 .)

From his observation of three cases, which he describes in detail, the writer concludes that it is legitimate to state that there exist two kinds of pseudo-membranous rhinitis, which are clinically identical and can only be distinguished by bacteriological examination.

The more frequent kind is of diphtheritic nature, the other, rarer, is due to various organisms, quite independent of Loeffler's bacillus.

Hence, in the matter of treatment, the second class does not necessarily respond to serum therapy. L. Graham Brown.

The Treatment of Epithelioma of the Deep Facial Structures. A. Hautant. (Annales des maladies de l'oreille, du larynx, du nez et du pharynx, I928.)

Recent work shows the need of treating epithelioma in this region by a combination of surgery and radiation (X-rays and radium).

The writer asks if better results can be obtained by surgical diathermy and its further developments than by the old method of surgical excision, and shows how the after-treatment by radiation can be made more effective.

$\mathrm{He}$ describes the characteristics of these epitheliomas, and the therapeutic difficulties they present according to their type-and hence their radio-sensitivity-and the extent of invasion of neighbouring structures-glands, skin, muscle, mucosa, and the orbital and ethmoid cavities.

He then reviews the results obtained in recent years according to the method used:-With simple surgery the results are bad; so bad that this can no longer be considered an effective single weapon. For radiation, whether employed alone as X-rays or radium, or in association with surgery, he quotes Barnes's method as giving the best result (4 I per cent. cures without recurrence over post-operative periods of from ten months to nine years). Barnes, after surgical removal of the growth, completes the operation by a free resection of the soft tissues of the cheek, so that any subsequent local recurrence can be seen and treated by diathermy, and makes an immediate application of radium ( 100 to $200 \mathrm{mgrms}$. filtered radium left in situ for 24 to 48 hours) to the more remote affected areas such as sphenoid, ethmoid, and pterygo-maxillary fossa.

$\mathrm{He}$ next describes the technique of diathermy and reviews the results of various workers using this method alone or combined with radio-therapy. He comes to these conclusions :-

Diathermy has distinct disadvantages when applied to extensive growths, and gives no better results than the ordinary methods when the growth is limited. 


\section{The Larynx}

We must look to radio-therapy for further improvement in our results, and our efforts in the future must be directed to the more scientific application of radiations before and after the removal of the tumour by the most complete method of surgery indicated.

A bibliography of recent work on the subject is appended.

L. Graham Brown.

\section{THE LARYNX.}

A New Technique for Laryngectomy. A. Sercer (Zagreb). (Revue de Laryngologie, 15 th February 1928.)

The author lays stress on the fact that the chief danger of laryngectomy is infection of the tissues around the stump of the trachea, by leakage from the pharyngeal wound. He considers that it is useless to attempt primary closure of the pharyngeal wound in the majority of cases. He states that, of the $3^{6}$ operations by Gluck's method which he had seen, in only one was primary union of the pharyngeal wound obtained. His operation includes a deliberately planned pharyngostomy, with suture of the mucous membrane to the skin margins. Other points to be aimed at are: (I) Free exposure of the whole field of operation. (2) A skin flap which will lie flat on the deep intersternomastoid hollow left by the removal of the larynx, without any "dead spaces." (3) Careful adaptation of the skin margins around the stump of the trachea.

The operation may be done in two or in three stages-(I) Mass dissection of the glands of the neck; (2) laryngectomy, with removal of as much of the pharyngeal wall as may be necessary; (3) closure of the pharyngeal opening. Stages (I) and (2) are usually done consecutively at the first operation, unless the glandular infection is too extensive. (3) Is a trivial operation which is carried out when the rest of the wound is soundly healed.

Laryngectomy.-The skin on the front of the neck is raised in one large horse-shoe flap with its base upwards, the convexity of which descends to the level of the cricoid. From the convex margin of this flap incisions are carried down on either side to the clavicles. The glands are dissected out en bloc and the larynx is removed with so much of the pharyngeal wall as may be necessary. A median vertical button-hole incision is made in the skin flap, corresponding in position with the pharyngeal opening, and the mucous membrane of the pharynx is accurately stitched to the margins of the skin-incision. The lower flap is carefully adapted around the sides of the stump of the trachea, to which it is sutured. The lowest part of the horseshoe flap is sutured to the back of the trachea. The lateral parts of the wound are left open, to secure free drainage, and obviate all tension. 


\section{Abstracts}

The skin flaps must fit down on to their bed, and must not bridge the gap between the edges of the sternomastoids so as to leave dead spaces. The author also insists on the importance of the skin flaps around the stump of the trachea being movable, so that they will yield to the movements of the trachea. No sutures will retain the stump of the trachea in position if the skin to which it is sutured is fixed.

At the conclusion of the operation a large rubber tube is introduced into the stomach through the pharyngostomy opening, and retained there. Through this the patient is fed. An ample dressing of iodoform gauze presses the flap down on to its bed, and prevents the soiling of the wound by saliva leaking from the pharyngostomy opening.

G. Wilkinson.

\section{Laryngeal Palsies. J. Ramadier. (Annales des maladies de l'oreille, etc., r928.)}

The writer holds, in opposition to the views of Dufourmentel, Truffert and Hegener, that there is both a clinical and a physiological distinction between the two classic laryngeal paralyses.

In the "open," "total" or "phonatory" paralysis the position of the cord is intermediate between adduction and abduction; the free border is sharp and concave; the whole cord atrophies, and appears to be shortened on account of the forward inclination of the arytenoid. There is complete aphonia in bilateral cases, a bitonal dysphonia in unilateral cases, but respiration is not affected.

In the "closed," "dilator" or "respiratory" paralysis, during inspiration the cord lies close to the mid-line (paramedian position) and, since the paralysis is nearly always bilateral, the glottic aperture is narrowed to $\mathrm{I}$ to $2 \mathrm{~mm}$. and may be completely closed during vocal effort; hence the cord is not, strictly speaking, immobilised. The appearance of the cord is otherwise normal, and phonation is normal except for interruptions due to the necessity for frequent respiration; there is, however, difficulty in producing modulations in tone, and there is considerable respiratory difficulty.

In each syndrome there is paralysis of a corresponding muscular territory; total laryngeal paralysis in one case, a paralysis confined to the dilators in the other.

Although experimental evidence does not always support his view, he believes that the innervation of the intrinsic muscles varies in respect of two nerves of supply, the superior and the recurrent. In conclusion he believes that, excluding cases where the causal diagnosis is clear, such as cervico-mediastinal affections, typhoid fever, etc., the others, and they are the majority, are due to syphilis.

\section{Graham Brown,}




\section{The Pharynx}

A Case of Sudden Death due to the Occlusion of the Larynx by two Ascaris lumbricoides. M. B. Duncan Dixey, Togoland, Gold Coast. (Edinburgh Medical Journal, February 1929.)

A female child, aged $8 \frac{1}{2}$ years, was sent to a well to draw water, with her small sister. The child arrived at the well, drew the water, and was carrying it back to the house, when she suddenly fell forward on her face, gasping for breath, and unconscious. She was carried into the house, where she died in less than three minutes. At the post-mortem examination, two large Ascaris lumbricoides worms were seen to be protruding from the larynx; on closer inspection one was seen to be partially curled up in the larynx, and between them the whole of the larynx was occluded, completely preventing respiration. On opening the trachea and bronchi, it was found that they were filled with froth, and the walls were injected; the vessels were filled with blood of a very dark colour. The right side of the heart was dilated, and the left side empty. No other pathological condition was found. In the stomach another Ascaris was found, and two more in the small intestine.

Death was probably due to asphyxia, the result of the complete occlusion of the larynx by these two worms.

Perhaps the more violent respiration, the result of the exertion of carrying the water, caused their inspiration into the larynx with complete occlusion and asphyxia.

Douglas Guthrie.

\section{THE PHARYNX.}

\section{A Basal-Celled Carcinoma associated with Persistent Lingual Duct.} Dotr. Vito Catania. (Archivii de Laryngologia, Anno xiviii. Fasc. 2, October 1928.)

The author describes the case of a woman of $3^{2}$ who had noticed a swelling in the back of her tongue for five months. Examination showed a swelling between the foramen cæcum and the epiglottis occupying all the right and part of the left half of the posterior third of the tongue. The surface was whitish, irregularly nodulated and not obviously ulcerated. It had grown rapidly in five months and did not appear to be thyroid tissue. It was removed by a subthyroid pharyngotomy, the wound closed and the patient discharged fifteen days later.

Microscopical examination revealed two zones-an outer one consisting of an epithelial covering with a thick layer of connective tissue and a central, or alveolar area. The epithelial covering was continued into the foramen cæcum, which led to the remains of the lingual duct, and in this region the epithelium was degenerate with 287 


\section{Abstracts}

areas of cavitation and destruction. The remains of the duct had become cystic by degeneration.

Surrounding the remains of the duct, and infiltrating the connective tissue, was a mass of large cells of which a great number were vacuolated and many degenerate. They were definitely of the basal epithelial type. The degeneration was so marked in places that cystic formation and a yellowish colour had resulted from fatty degeneration. It was noticeable that karyokinetic figures were absent from the sections.

\section{F. C. ORMERoD.}

\section{The Significance of the Disturbance of Speech and Graphic Registration of the Function of the Soft Palate in the early Diagnosis of Myasthenia. Dr M. Seemann, Prague. (Otolaryngologia Slavica, Vol. i., Fasc. I, p. 73.)}

The author was able in several cases of myasthenia to make an early diagnosis by means of systematic graphic investigation of the speech. Tracings are taken from a drum connected with the nose on the one hand and the mouth on the other, and it is found that the nose tracing soon becomes irregular and more extensive, while the tracing from the mouth becomes smaller, showing the rapid exhaustion of the soft palate. The characteristic tracings are illustrated in this article. In cases with any suspicion of the presence of myasthenia gravis, notice should be taken of the degree of rapidity with which the speech acquires the rhinolalial character, but if this is not obvious he should be made to read aloud until it does occur, if present. The exhaustion of the muscles of articulation may be tested by causing the patient to utter continuously such syllables as " $p a$," " $p i$ " (German pronunciation). Several cases are described and the stages into which the disease may be divided are classified as "the prodromal" and "the well developed." Myasthenia may show itself primarily in the muscles supplied by the bulbar nerves, but in other cases it begins in the muscles of the limbs. He recommends that along with laryngorhinological examination, the possibility of myasthenia should always be kept in view if the patient, in spite of negative objective data, complains of the occasional occurrence of rhinolalia aperta.

\section{James Dundas-Grant.}

\section{Actinomycosis of the Nasopharynx. Dotr. Tonio MagnotTr. (Archivio Italiano di Otologia, Vol. xxxix., Fasc. 2, 1928.)}

The writer has encountered two cases in which the nasopharyngeal tonsil was infected by actinomyces. The first case was a young man of 28 years who had suffered from shortness of breath, from extreme loss of fat in the subcutaneous tissue, and a blood-stained sputum. Tuberculosis was suspected but no sign could be found. Eventually 


\section{The Pharynx}

a pad of adenoids was suspected of being the cause and was removed. Microscopic examination showed granulation tissue, a margin of lymphoid elements, and a branching fungus with club-shaped extremities.

The second case was in a man 25 years who had a discharge from the right ear. The discharge was yellowish, and there was a very large perforation, leaving only the postero-superior quadrant of the tympanic membrane. A large mass of adenoids was found and promptly removed. The ear was treated antiseptically, and healed in fifteen days. Following the previous case, actinomycosis was suspected and a culture made in broth and a subculture on agar. Only staphylococci and streptococci were grown, but microscopic section again showed the presence of the fungus.

Actinomycosis is uncommon in the nasopharynx, but in a case reported by Alagna it occurred in a child of 6 years. The fungus tends to be located in the centre of a lymphoid follicle, and in the follicles nearest to the covering epithelium. Giant cells were found, and also epithelial cells with granulation tissue and a leucocytic infiltration.

F. C. Ormerod.

Chronic Angina of the Styloid Process. J. SAREL. (Annales des maladies de Toreille, du larynx, du nez, et du pharynx, August 1928.)

By this term the writer describes a definite condition wherein the patient complains of painless dysphagia, and sometimes slight earache; but chiefly of a vague sensation of annoyance, pain and swelling in the region of the tonsil. On examination no inflammation can be seen, but the finger detects an elongated styloid process which can be confirmed by radiography. Hence the importance of digital examination in such patients before relegating them to the ranks of the neurotics. Precise diagnosis generally suffices to relieve the patient's mind of his fear of cancer or tuberculosis ; sometimes surgical interference, preferably by the external route in view of neighbouring important structures, may be necessary.

Sarel cites four cases to illustrate the importance of diagnosis, and explains the best method of taking lateral skiagrams to show the abnormality. He suggests that the pathology of the condition is an ossification of the cerato-hyal portion of the stylo-hyoid ligament taking place in middle adult life. L. GRAHAM Brown.

Tonsillectomy in Chronic Arthritis. Dr A. B. Pavey-Smith. (Lancet, 1929, Vol. i., p. I70.)

The author reports on 200 cases operated on at the Royal Bath Hospital, Harrogate, and his conclusions are interesting. A probable tonsil focus can be found in a large number of cases of subacute VOL. XLIV. No. IV. 289 


\section{Abstracts}

rheumatism, chronic infective (focal) arthritis, and fibrositis. Before deciding on tonsillectomy it is necessary to consider history, size, colour, crypt contents, and associated lymphatic glands, and in selecting cases for operation a history of tonsillitis associated with onset or recurrences is favourable in cases of infective (focal) arthritis, and to a lesser extent in subacute rheumatism, where such a history is more common. The younger the patient and the shorter the duration of disease, the better the prospects, but within very wide limits neither age nor duration are a bar to success. Dr Pavey-Smith's research increases the suspicion attached to the streptococcus viridans as the primary agent in chronic focal arthritis, but is not conclusive. In the subacute rheumatism group, the results of tonsillectomy are so good that it has become a routine part of the treatment, if only as a prophylactic against recurrences and later endocarditis. In cases of chronic focal arthritis, if the balance of evidence condemns the tonsil and complete excision is performed, improvement may be expected in 80 per cent. of cases. Macleod Yearsley.

Tonsillar Hypertrophy and Infection as a Factor of Ill-health. Donald Paterson and G. W. Bray. (Lancet, 24th Nov. 1928, Vol. ii., 1074.)

This is an analysis of 500 cases from the out-patient department of the Great Ormond Street Hospital for Children, and demonstrates the efficacy of tonsillectomy in selected cases. Five hundred children attending hospital complaining of various symptoms, and who were found to have septic or hypertrophied tonsils, reacted "in an almost uniformly satisfactory manner to tonsillectomy," and rapidly gained weight. The authors used a dissection operation, and stress the importance of including the lingual tonsil in the extirpation. The remark that "a few had had their tonsils guillotined elsewhere previously, and along with their recurrence was a return of symptoms" is very significant.

MACLEOD Yearsley.

\section{ESOPHAGUS AND ENDOSCOPY.}

Contribution on the Clinical and Pathological Anatomy of Carcinoma of the CEsophagus. Dr Helmuth Richter. (Archiv fiir Ohren-, Nasen-, und Kehlkopfheilkunde. Band cxix., Heft 3/4. November 1928.)

Richter describes the main clinical features of fifty-two cases of malignant œsophageal stricture, and discusses the histology of new growths in this situation. Cases have occurred four times more frequently at the Halle Clinic recently than before the War.

290 


\section{Esophagus and Endoscopy}

Richter is able to speak of two cases as cured, and he believes that there is a possibility of this achievment being repeated in a somewhat larger percentage of cases by using radium in larger doses. The paper is presented in the form of a critical review, with references to recent writings on the subject. He does not give a detailed account of the radium technique in the two successful cases. W. O. LoDGE.

Rupture of the (Esophagus by Indirect Violence. J. R. MURDOCH. (Lancet, 1928, Vol. II., x292.)

The author describes the case of a boy aged 6, run over by a motor cycle. He was bleeding from nose and mouth, unconscious, and died a few hours after admission. The œsophagus was torn longitudinally for $1 \frac{1}{4}$ inches, $\frac{3}{4}$ inch above the diaphragm. The left pleural cavity contained dark reddish-brown fluid and particles of food. There were other serious injuries, including a fracture of the skull with extensive extradural hæmorrhage.

MaCleod Yearsley.

Recurrent Nerve Paralysis in Cancer of the Esophagus. A. SARgnon. (Archives Internationales de Laryngologie, November 1928.)

Bilateral recurrent nerve palsies in cancer of the œsophagus are uncommon. Two clinical types can be recognised : the dyspnoic and the aphonic. In the former, there is marked abduction of the vocal cords, and the voice, though hoarse, is present. Dyspnœa, at first intermittent, becomes continuous and soon necessitates a tracheotomy. The prognosis in such cases is extremely grave and heralds a speedy termination.

Evolution of the aphonic form is much slower. Two stages are observed. First a unilateral paralysis, usually on the left side, the paralysed cord soon passing from the median to the cadaveric position. Later, the other cord is affected, and the patient becomes aphonic. The author believes that these two forms are expressions of the rapidity of the evolution of the disease.

To avoid a calamity from performing endoscopy in a case of aortic aneurysm in the belief that the condition is oesophageal carcinoma, the author points out how the differential diagnosis should be made. Recurrent nerve paralysis occurs in 7 to to per cent. of cases of cesophageal cancer, and in 30 per cent. of cases of aortic aneurysm. In both cases, it is commoner on the left side, but where the paralysis is on the right side, the condition is more likely to be one of œsophageal cancer.

Michael Vlasto.

VOL. XLIV. NO. IV. 


\section{Abstracts}

Methods of Simplifying the Extraction of Foreign Bodies from the Alimentary and Respiratory Tracts. S. BÉLINoFF. (Archives Internationales de Laryngologie, November 1928.)

Foreign bodies should be removed as soon as possible after their impaction. But, whereas impaction in the respiratory tract necessitates their extraction in an upward direction, endoscopists are apt to overlook the fact that impaction in the cesophagus is often best dealt with by disimpaction into the stomach.

It is established that disimpaction of a foreign body may occur under the following conditions:

(I) Spontaneous: where the foreign body is released and passed on by spontaneous physiological activity.

(2) Mechanical: when the foreign body is recognised through the cesophagoscope and is lost to view. Later, it is expelled per anum. In such cases, it is assumed that the csophagus has been dilated by the instrument and the foreign body released.

(3) Disimpaction by means of local anæsthesia (cocain 5 to 20 per cent.)

(4) Disimpaction under general anæsthesia.

(5) Disimpaction by special methods of cesophageal distension with rubber balloons filled with air or water.

Numerous cases are quoted of foreign bodies removed by one or other of the above methods. The author recognises, however, that a dramatic instrumental removal is likely to remain the method of choice.

The author stresses the fact that foreign bodies in the respiratory tract occur nearly always in children. He agrees with other bronchoscopists in stating that in children below the age of six inferior bronchoscopy should be carried out. He finds, however, that the simplest and best method of extraction is to introduce an ordinary nasal speculum into the tracheotomy wound, and extract the foreign body with nasal forceps. Cases are quoted of removal by this method.

Michael Vlasto.

\section{MISCELLANEOUS.}

Clinical Picture of Myxadema, Especially of the Ear, Throat and Nose. Six Original Cases. Dr MANN (Dresden). (Zeitschrift für Hals-, Nasen-, und Ohrenheilkunde, Band xxii., Heft 2, p. 145.)

(I) A man, aged $5 \mathrm{I}$, complained of difficulty in speaking and lecturing, and frequent failure in utterance, lowering of hearing-power and of smell; at night the difficulty amounted to cessation of breathing. In addition, as compared with their previous condition, the face was 


\section{Miscellaneous}

thick and shapeless, the hands broader and thicker, "pins and needles" in the fingers, lowering of sense of touch, absence of perspiration, continuous coldness; the dullness of the left ear was of the nature of nerve deafness; there was spontaneous past-pointing with the left arm inwards. After taking Merck's thyreoidin (I decigramme thrice daily) for a fortnight, very striking improvement showed itself.

(2) A man, aged 6o, with history of luetic infection nine years previously, developed characteristic signs of myxœdema, including coldness of the whole of the body. The voice was dull and toneless and there was difficulty in swallowing. The Wassermann reaction was positive and specific treatment was started, but instead of improvement a very rapid deterioration took place. Nothing characteristic was then seen in the larynx. When thyroid treatment was administered, such a rapid improvement took place that in a few months he was again fit for agricultural labour.

(3) A woman, aged 38 , with luetic infection at the age of 20. There was a mass of lymphatic glands of hard consistence under and external to the sternomastoid muscle on each side. She was treated with neosalvarsan, but bismuth was substituted for it, and neosalvarsan was resumed at a later date. It produced, however, an itching erythema which disappeared under calcium treatment. Two months later the myxœedematous condition developed. Thyreoidin was given, and after fourteen days the greater part of her discomfort disappeared. It is probable that the syphilitic infiltration of the glands extended into the thyroid body and induced a sclerosis with resulting hypothyroidism.

(4) A woman, aged 25 , had had frequent tonsillar abscesses, and tonsillectomy was carried out. Six months later she woke in the night with violent dyspnca, sore throat and pain on swallowing. CEdema of the upper ring of the larynx was found and was attributed to cryptogenic perichondritis. Warmth and scarification produced no improvement and rigors and pyrexia ensued. After two months of illness the writer found a straining and absence of tone in the speech, striking hardness of the soft palate, and odema of the uvula, a high degree of thickening of the epiglottis and of the aryepiglottic folds; these separated very slightly during inspiration. The patient continued in a feverish condition for three months without any relief being afforded; the appearance in the larynx remained unchanged, and only some months later, after all other possibilities had been excluded, a diagnosis of myxoedema was made. Rheumatic and neuralgic pains were present in all the limbs; there was headache, difficulty in walking, chilliness of the whole body, etc. Thyroid treatment brought about an astoundingly good result. The fever disappeared on the ninth day after having been present uninterruptedly for six months. The 


\section{Abstracts}

swelling of the larynx diminished; the difficulty in breathing disappeared and the voice improved. Ultimately the patient started work again.

(5) A woman, aged 55, had previously had mild Basedow's disease and underwent the appropriate operation on her thyroid gland. She subsequently went through a period of very great anxiety and lost flesh to an alarming extent. To her great astonishment she began to get fat, especially about the cheeks and hands, and instead of unbearable heat from which she had suffered, she became chilly all over. Her voice became hoarse and she experienced considerable obstruction in the nose with secretion of mucus in the throat; she was referred to the writer on the supposition that she had polypi. The nose was found to be narrowed, the mucous membrane pale, the turbinated bodies thick and covered with stringy mucus. The arytenoids were pale and greatly swollen. She was extremely anæmic. She appears to have refused further treatment.

(6) A man, aged $3^{8}$, had had left-sided goitre, which had been removed by operation. The right side of the neck began to swell. $\mathrm{He}$ was quite hoarse, suffered from difficulty in breathing, with a feeling of chilliness and fatigue. His face became broader and generally swollen, the nose strikingly wide. A diagnosis of myxœdema was made, due probably to the thyroid tissue having degenerated. Under thyreoidin treatment a striking improvement took place in seven days. The laryngoscope showed a sluggishness of movement of the vocal cords and marked odema of the left aryepiglottic fold. He continued taking tabloids of thyreoidin without interruption until in one year he had taken as many as 300 . He then developed some of the features of Grave's disease, such as exophthalmos, and very dilated pupils, but without any of the other signs. This condition is attributed to excessive dosing with thyreoidin.

James Dundas-Grant.

Intradermic Injections of Peptone in the Treatment of Hay Fever. M. JАСО. (Ann. des maladies de l'oreille, etc., May r 928.)

The writer reports the results of intradermic injections of peptone in ten patients during the hay fever season of $19^{27}$.

The technique consists in daily injections into the true dermis of minimal doses, not exceeding $0.3 \mathrm{ccm}$., of a 50 per cent. solution of Witte's peptone over a period of 20 days ; the period may be increased to 30 according to the periodicity of the malady.

At present the most that can be said for the method is that it is simple, cheap, free from danger, and capable of giving some relief of symptoms, without a definite cure. It is superior to the non-specific methods of desensitisation (autosero- and auto-hæmotherapy), no 


\section{Miscellaneous}

better than galvano-cautery of the inferior turbinals, and much inferior to such methods of antianaphylaxis as injection of progressive dilutions of pollens, although these may cause violent urticarial or asthmatic reactions.

Further trial of the method is warranted, especially as to its value as a desensitiser or prophylactic before the onset of symptoms.

\section{Graham Brown.}

\section{A Severe "Relapse" in a Case of Diphtheria.}

A. H. G. Burton and A. R. Balmain (Lancet, 1928, vol. ii., p. 1182) narrate the case of a female, aged I9, who after a moderately severe attack of faucial diphtheria, developed a second attack $3 \mathrm{I}$ days later.

This relapse was severe and recovery was slow. The family history was interesting. The patient herself had scarlet-fever at 6 , and "relapsed," and was Dick-negative and Schick-positive. The brother, aged I 3, had two attacks of scarlet-fever in one year, was Dick-negative, but Schick-positive. The father was Schick-negative and Dick-negative, and had had neither scarlet-fever nor diphtheria. The mother had scarlet fever at 4 , and was Schick-negative, but Dick-positive. Neither she nor the brother had had diphtheria.

Relapse in diphtheria is extremely rare, and this case is the first seen by the reporters in a series of over I Ioo. It is of interest owing to :-

I. The severity of the relapse.

2. The fact that 33 days after the relapse and 64 days after the primary attack the patient had not developed immunity.

3. That in spite of this, an immunity, although it may prove to be temporary, was acquired by injections of toxoid antitoxin mixture.

Macleod Yearsley.

\section{Agranulocytic Angina. A. Geschelin, Odessa. (Acta Oto- Laryngologica, Vol. xii., fasc. 3.)}

Changes in the mucosa of the upper respiratory passages and the œsophagus in diseases of the blood and organs of the hæmopœtic system have been known for a relatively long time. Virchow pointed out epistaxis as a cardinal symptom in leukæmia. A necrobiotic process is common to these various changes. They are observed in acute and chronic leukæmias often when the clinical picture is already complete, but occasionally cases have been described where they were essentially the first symptoms of some grave blood disease.

Some years ago attention was attracted to a special syndrome which was accompanied by characteristic changes in the mucosa of 


\section{Review of Book}

the upper respiratory passages as the first indication of a grave blood disease or of one of the hæmopœtic system.

In July I 922 at Berlin, Schultz and Freedman at the same meeting described a new syndrome called by Schultz agranulocytosis. The special symptoms of the malady were an almost complete disappearance in the blood of granulocytes, and further, a series of characteristic lesions of the necrotic and gangrenous type in the buccal cavity and the pharynx. Since these observations many records of similar cases have been published.

Women are the chief victims. The disease starts acutely without prodromal symptoms, with general symptoms of malaise, joint pains and fever. Angina is a marked sign, and is very like that of diphtheria or of Plaut Vincent. The tonsils, palate, tongue, mucosa of the cheeks, and the gums, are affected, with extension into the deep pharynx, larynx, and trachea. The genitalia and the œsophagus may also be attacked.

The second cardinal sign is to be found in the hæmatogram, particularly in the leucocyte picture. Their total falls to several hundreds. Granulocytes disappear absolutely.

The etiology is obscure. Freedman suggested a special type of septicæmia, but the blood has been repeatedly found to be sterile.

The prognosis is nearly always fatal; men, however, having been known to recover.

The author describes his own case in a woman of 49 years.

H. V. Forster.

\section{REVIEW OF BOOK}

Sinus Thrombophlebitis. By Alfred Braun, M.D., Oto-Laryngologist,

Hospital for Joint Diseases, New York. Published by the Oxford University Press. Price $\mathcal{E}_{2}$, 12s. 6d.

Dr Alfred Braun has written the book to call attention to the importance of general sepsis of otitic origin. The book consists of 25 I pages with II i illustrations and an extensive bibliography. Many of the illustrations are original and drawn by the author, which makes them more useful. The book is expensively and well produced on the best paper.

The first chapter is devoted to the development of the veins of the head and of the venous sinuses of the dura mater.

Chapter II gives the anatomy of the venous circulation of the head, and particularly that of the intra-cranial venous channels, and is well illustrated. The various abnormalities of the torcular herophili. 